\title{
Comprehensive Models for Evaluating Rockmass Stability Based on Statistical Comparisons of Multiple Classifiers
}

\author{
Longjun Dong and Xibing Li \\ School of Resources and Safety Engineering, Central South University, Changsha 410083, China \\ Correspondence should be addressed to Longjun Dong; rydong001@csu.edu.cn
}

Received 14 July 2013; Accepted 7 August 2013

Academic Editor: Baochang Zhang

Copyright (C) 2013 L. Dong and X. Li. This is an open access article distributed under the Creative Commons Attribution License, which permits unrestricted use, distribution, and reproduction in any medium, provided the original work is properly cited.

\begin{abstract}
The relationships between geological features and rockmass behaviors under complex geological environments were investigated based on multiple intelligence classifiers. Random forest, support vector machine, bayes' classifier, fisher's classifier, logistic regression, and neural networks were used to establish models for evaluating the rockmass stability of slope. Samples of both circular failure mechanism and wedge failure mechanism were considered to establish and calibrate the comprehensive models. The classification performances of different modeling approaches were analyzed and compared by receiver operating characteristic (ROC) curves systematically. Results show that the proposed random forest model has the highest accuracy for evaluating slope stability of circular failure mechanism, while the support vector Machine model has the highest accuracy for evaluating slope stability of wedge failure mechanism. It is demonstrated that the established random forest and the support vector machine models are effective and efficient approaches to evaluate the rockmass stability of slope.
\end{abstract}

\section{Introduction}

Since their introduction, researches into the areas of machine learning and their applications continue to captivate scientists and engineers from a variety of disciplines. This growing interest among researchers is stemming from the fact that these learning machines have an excellent performance in the issues of pattern recognition and the modeling of nonlinear relationships of multivariate dynamic systems [1]. The widely used and representative classification methods include random forest, support vector machine, baye's classifier, fisher's classifier, logistic regression, and neural networks.

Comprehensive classification of slope rockmasses, an important activity during exploration, design, and construction for underground openings, is restrained by our limitations in defining the complex geological environments and modeling the relationships between geological features and rockmass behaviors $[2,3]$. The published literatures reporting on learning machines provided effective and efficient approaches to establish the nonlinear relationships between geological features and rockmass behaviors $[4,5]$.

Some recent publications on various geotechnical engineering topics using different methods are given as follows: remote sensing and GIS based landslide susceptibility assessment [6]; landslide susceptibility mapping [7-9]; early warning landslide susceptibility model using geographic information system (GIS) [10]; regional prediction of landslide hazard [11]; predicting of rockburst classification [12, 13]; predicting destructive effect of masonry structure under blasting vibration of open-pit mine [14]; prediction of seismic liquefaction of sand soil [15]; classification of rocks surrounding in tunnel $[16,17]$; classification of top coal cavability of the steep seam [18]; comprehensive evaluation for seismic stability of slopes [19]; prediction rock mechanical behaviors [4]; predicting landslide deformation [20, 21]; predicting of P-wave velocity and anisotropic property of rock [22]; estimating rock properties using sound levels produced during drilling [23]; automated tunnel rock classification using rock engineering systems [24]; estimation of the rock mass deformation modulus using a rock classification system [25]; predicting blast disaster in open pit blasting operation [26, 27]; evaluation of penetration rate of tunnel boring machine in hard rock condition [28]; comparative study of cognitive systems for ground vibration measurements [29]; prediction of longitudinal wave velocity [30]; optimization of tunnel construction [31]; prediction of the rock mass diggability 
index [32]; prediction of rock properties from sound levels produced during drilling [5]; modeling mine gas gushing forecasting on virtual environment [33]; rainfall reliability evaluation for stability of municipal solid waste landfills on slope [34]; determination of reservoir induced earthquake [35]; seismic event identification [36]; and prediction of elastic modulus of jointed rock mass [37].

However, researchers study the applications of support vector machine, bayes' classifier, fisher's classifier, logistic regression, and neural networks for evaluating rockmass stability, but few focus on applications of the advanced random forest method in the area, especially that few focus on the overall comparison of performances of different classifiers.

This paper investigated the validity of utilizing different learning machines in the physical problem of slope stability prediction. Random forest, support vector machine, bayes' classifier, fisher's classifier, logistic regression, and neural networks were used to establish comprehensive models for evaluating rockmass stability of slope, and the classification performances of different modeling approaches are analyzed and compared using ROC curves.

\section{Data, Models, and Results}

2.1. Data. The main scope of this work is to implement the random forest, support vector machine, bayes' classifier, fisher's classifier, logistic regression, and neural networks in the problem of slope stability estimation. In order to forecast the status of stability $(S)$ in the case of rock or soil slopes, the factors that influence $S$ have to be determined. The input layer data consist of six input parameters in the case of circular failure and eight input parameters in the case of wedge failure. The output layer is composed of a single output parameter, the status of stability $(S)$. In this work, the status of stability is considered as a function approximation problem taking values in the range of $[0,1]$, instead of the discrete values 0 and 1 , with 1 indicating stable and 0 indicating failed.

The datasets used in this paper were collected from the publication by Sakellariou and Ferentinou [1]. The first dataset consists of 46 case studies of slopes analyzed for circular critical failure mechanism. Of them, 23 cases are dry (13 failed and 10 stable) and 23 cases are wet (16 failed and 7 stable). The second dataset consists of 22 case studies of rock slopes analyzed for wedge failure mechanism. All cases are dry (10 failed and 12 stable). The original data covering the 46 case studies are presented in Table 1, while the original data covering the 22 case studies are presented in Table 2 . In the tables, $F$ is the safety factor. The parameters that have been selected are related to the geotechnical properties and the geometry of each slope. More specifically, the parameters used for circular failure (Figure 1(a)) were unit weight $(\gamma)$, cohesion $(c)$, angle of internal friction $(\phi)$, slope angle $(\beta)$, height $(H)$, and pore water pressure $\left(r_{u}\right)$. In the case of wedge failure (Figure 1(b)), the corresponding input parameters were unit weight $(\gamma)$, cohesions $\left(c_{A}\right)$ and $\left(c_{B}\right)$, angles of internal friction $\left(\phi_{A}\right)$ and $\left(\phi_{B}\right)$, angle of the line of intersection of the two joint sets $\left(\psi_{p}\right)$, slope angle $\left(\psi_{s}\right)$, and height $(H)$, where $A$ and $B$ refer to the two joint sets.
2.2. Random Forest Models. The random forest [38] is an ensemble approach that can also be thought of as a form of the nearest neighbor predictor. Random forests are an ensemble learning method for classification (and regression) that operates by constructing a multitude of decision trees at training time and outputting the class that is the model of the classes output by individual trees. The algorithm for inducing a random forest was developed by Breiman [38] and Adele Cutler, and "Random Forests" is their trademark.

The principle of random forests (RFs) is the aggregation of a large ensemble of decision trees [38]. During training, each individual tree in the ensemble is fitted by sampling the training data with replacement (bootstrap) and growing the tree to full depth on the training sample. The optimal data split at each tree node is determined by randomly choosing $m$ of the available $P$ input variables and selecting the one which splits the node best.

This implementation is based on the original Fortran code authored by Breiman, the inventor of RFs. We considered different parameter configurations for the values of $n_{\text {tree }}=$ 300,500 , and 1000 (number of trees to build) and nodesize $=$ 2 (minimal size of the terminal nodes of the tree). The results for circular failure mechanism and wedge failure mechanism are listed in Tables 1 and 2.

2.3. Support Vector Machine Models. The extensive applications literature on text categorization, image recognition, rock mechanics and other fields shows the excellent empirical performance of support vector machine (SVM) in many more domains $[4,39]$. The underlying idea of SVM classifiers is to calculate a maximal margin hyperplane separating two classes of the data.

To learn nonlinearly separable functions, the data are implicitly mapped to a higher-dimensional space by means of a kernel function, where a separating hyperplane is found. New samples are classified according to the side of the hyperplane they belong to [22]. Many extensions of the basic SVM algorithm can handle multicategory data. The "oneversus-rest" SVM works better for multiclass microarray data $[1,6]$, so this method was adopted for the analysis of multicategory datasets in the present study. In summary, this approach involves building a separate SVM model to classify each class against the rest and then predict the class of a new sample using the SVM model with the strongest vote.

We used SVM implementation in the DPS software with $\mathrm{RBF}$ kernel. The type of support vector machine is C-SVC, the kernal function is RBF, and $C$ value is 1 . The results for circular failure mechanism and wedge failure mechanism are listed in Tables 1 and 2, respectively.

2.4. Bayes' Classification Models. The aim of the naive bayesian classifier (NBC), as with other classifiers, is to assign an object $I$ to one of discrete sets of categories $C_{1}, C_{2}, \ldots, C_{m}$ based on its observable attributes $X_{1}, X_{2}, \ldots, X_{n}$. NBCs are used in a variety of applications, including document classification, medical diagnosis [40], systems performance management, probability classification of rockburst [41], and other fields. Domingos and Pazzani [42] proved optimality of 
TABLE 1: Samples for circular failure mechanism and results.

\begin{tabular}{|c|c|c|c|c|c|c|c|c|c|c|c|c|c|c|c|}
\hline Case no. & $\gamma\left(\mathrm{KN} / \mathrm{m}^{3}\right)$ & $C(\mathrm{kPa})$ & $\Phi\left(^{\circ}\right)$ & $\beta\left(^{\circ}\right)$ & $H(\mathrm{~m})$ & $r_{u}$ & $S$ & $F$ & Moisture & Bayes & Fisher & SVM & LR & $\mathrm{BP}$ & $\mathrm{RF}$ \\
\hline 1 & 18.68 & 26.34 & 15 & 35 & 8.23 & 0 & Failed & 1.11 & Dry & 0 & 0 & 0 & 0 & 0 & 0 \\
\hline 2 & 21.4 & 10 & 30.34 & 30 & 20 & 0 & Stable & 1.7 & Dry & 1 & 1 & 1 & 1 & 1 & 1 \\
\hline 3 & 23 & 0 & 20 & 20 & 100 & 0.3 & Failed & 1.2 & Wet & 0 & 0 & 0 & 0 & 0 & 0 \\
\hline 4 & 16 & 70 & 20 & 40 & 115 & 0 & Failed & 1.11 & Dry & 0 & 0 & 0 & 0 & 0 & 0 \\
\hline 5 & 18.84 & 14.36 & 25 & 20 & 30.5 & 0.45 & Failed & 1.11 & Wet & 0 & 1 & 0 & 0 & 0 & 0 \\
\hline 6 & 20 & 0 & 36 & 45 & 50 & 0.5 & Failed & 0.67 & Wet & 0 & 0 & 0 & 0 & 0 & 0 \\
\hline 7 & 18.5 & 12 & 0 & 30 & 6 & 0 & Failed & 0.78 & Dry & 0 & 0 & 0 & 0 & 0 & 0 \\
\hline 8 & 22 & 20 & 36 & 45 & 50 & 0 & Failed & 1.02 & Dry & 0 & 0 & 0 & 0 & 0 & 0 \\
\hline 9 & 12 & 0 & 30 & 35 & 4 & 0 & Stable & 1.46 & Dry & 0 & 0 & 1 & 0 & 1 & 1 \\
\hline 10 & 21.43 & 0 & 20 & 20 & 61 & 0.5 & Failed & 1.03 & Wet & 0 & 0 & 0 & 0 & 0 & 0 \\
\hline 11 & 22 & 0 & 40 & 33 & 8 & 0.35 & Stable & 1.45 & Wet & 1 & 1 & 1 & 1 & 1 & 1 \\
\hline 12 & 20.6 & 16.28 & 26.5 & 30 & 40 & 0 & Failed & 1.25 & Dry & 1 & 1 & 0 & 1 & 0 & 0 \\
\hline 13 & 18 & 5 & 30 & 20 & 8 & 0.3 & Stable & 2.05 & Wet & 1 & 1 & 1 & 1 & 1 & 1 \\
\hline 14 & 23.47 & 0 & 32 & 37 & 214 & 0 & Failed & 1.08 & Dry & 0 & 0 & 0 & 0 & 0 & 0 \\
\hline 15 & 20 & 20 & 36 & 45 & 50 & 0.5 & Failed & 0.83 & Wet & 0 & 0 & 0 & 0 & 0 & 0 \\
\hline 16 & 20.41 & 24.9 & 13 & 22 & 10.67 & 0.35 & Stable & 1.4 & Wet & 0 & 0 & 1 & 0 & 0 & 1 \\
\hline 17 & 18 & 24 & 30.15 & 45 & 20 & 0.12 & Failed & 1.12 & Wet & 0 & 0 & 0 & 0 & 0 & 0 \\
\hline 18 & 28.44 & 39.23 & 38 & 35 & 100 & 0 & Stable & 1.99 & Dry & 1 & 1 & 1 & 1 & 1 & 1 \\
\hline 19 & 21.51 & 6.94 & 30 & 31 & 76.81 & 0.38 & Failed & 1.01 & Wet & 0 & 0 & 0 & 0 & 0 & 0 \\
\hline 20 & 22.4 & 10 & 35 & 45 & 10 & 0.4 & Failed & 0.9 & Wet & 0 & 0 & 0 & 0 & 0 & 0 \\
\hline 21 & 14 & 11.97 & 26 & 30 & 88 & 0 & Failed & 1.02 & Dry & 0 & 0 & 0 & 0 & 0 & 0 \\
\hline 22 & 22 & 0 & 36 & 45 & 50 & 0 & Failed & 0.89 & Dry & 0 & 0 & 0 & 0 & 0 & 0 \\
\hline 23 & 20 & 0 & 24.5 & 20 & 8 & 0.35 & Stable & 1.37 & Wet & 1 & 1 & 1 & 1 & 1 & 1 \\
\hline 24 & 28.44 & 29.42 & 35 & 35 & 100 & 0 & Stable & 1.78 & Dry & 1 & 1 & 1 & 0 & 1 & 1 \\
\hline 25 & 25 & 120 & 45 & 53 & 120 & 0 & Stable & 1.3 & Dry & 1 & 1 & 1 & 1 & 1 & 1 \\
\hline 26 & 19.63 & 11.97 & 20 & 22 & 12.19 & 0.405 & Failed & 1.35 & Wet & 0 & 0 & 0 & 0 & 0 & 0 \\
\hline 27 & 20.41 & 33.52 & 11 & 16 & 45.72 & 0.2 & Failed & 1.28 & Wet & 0 & 0 & 0 & 0 & 0 & 0 \\
\hline 28 & 22.4 & 100 & 45 & 45 & 15 & 0.25 & Stable & 1.8 & Wet & 1 & 1 & 1 & 1 & 1 & 1 \\
\hline 29 & 18.84 & 14.36 & 25 & 20 & 30.5 & 0 & Stable & 1.875 & Dry & 1 & 1 & 1 & 1 & 1 & 1 \\
\hline 30 & 12 & 0 & 30 & 45 & 8 & 0 & Failed & 0.86 & Dry & 0 & 0 & 0 & 0 & 0 & 0 \\
\hline 31 & 18.84 & 15.32 & 30 & 25 & 10.67 & 0.38 & Stable & 1.63 & Wet & 1 & 1 & 0 & 1 & 1 & 0 \\
\hline 32 & 21.82 & 8.62 & 32 & 28 & 12.8 & 0.49 & Failed & 1.03 & Wet & 1 & 1 & 0 & 1 & 1 & 0 \\
\hline 33 & 16.5 & 11.49 & 0 & 30 & 3.66 & 0 & Failed & 1 & Dry & 0 & 0 & 0 & 0 & 0 & 0 \\
\hline 34 & 9.06 & 11.71 & 28 & 35 & 21 & 0.11 & Failed & 1.09 & Wet & 0 & 0 & 0 & 0 & 0 & 0 \\
\hline 35 & 12 & 0 & 30 & 45 & 8 & 0 & Failed & 0.8 & Dry & 0 & 0 & 0 & 0 & 0 & 0 \\
\hline 36 & 18.5 & 25 & 0 & 30 & 6 & 0 & Failed & 1.09 & Dry & 0 & 0 & 0 & 0 & 0 & 0 \\
\hline 37 & 20 & 20 & 36 & 45 & 50 & 0.25 & Failed & 0.96 & Wet & 0 & 0 & 0 & 0 & 0 & 0 \\
\hline 38 & 18.84 & 57.46 & 20 & 20 & 30.5 & 0 & Stable & 2.045 & Dry & 1 & 1 & 0 & 1 & 0 & 0 \\
\hline 39 & 24 & 0 & 40 & 33 & 8 & 0.3 & Stable & 1.58 & Wet & 1 & 1 & 0 & 1 & 1 & 1 \\
\hline 40 & 26 & 150.05 & 45 & 50 & 200 & 0 & Stable & 1.2 & Dry & 1 & 1 & 1 & 0 & 0 & 1 \\
\hline 41 & 14.8 & 0 & 17 & 20 & 50 & 0 & Failed & 1.13 & Dry & 0 & 0 & 0 & 0 & 0 & 0 \\
\hline 42 & 12 & 0 & 30 & 35 & 4 & 0 & Stable & 1.44 & Dry & 0 & 0 & 0 & 0 & 1 & 1 \\
\hline 43 & 22.4 & 10 & 35 & 30 & 10 & 0 & Stable & 2 & Dry & 1 & 1 & 1 & 1 & 1 & 1 \\
\hline 44 & 18.84 & 0 & 20 & 20 & 7.62 & 0.45 & Failed & 1.05 & Wet & 0 & 0 & 0 & 0 & 0 & 0 \\
\hline 45 & 20 & 0 & 36 & 45 & 50 & 0.25 & Failed & 0.79 & Wet & 0 & 0 & 0 & 0 & 0 & 0 \\
\hline 46 & 14 & 11.97 & 26 & 30 & 88 & 0.45 & Failed & 0.625 & Wet & 0 & 0 & 0 & 0 & 0 & 0 \\
\hline
\end{tabular}


TABLE 2: Samples for wedge failure mechanism and results.

\begin{tabular}{|c|c|c|c|c|c|c|c|c|c|c|c|c|c|c|c|c|c|}
\hline No. & $\left(\mathrm{KN} / \mathrm{m}^{3}\right)$ & $c_{A}(\mathrm{KPa})$ & $c_{B}(\mathrm{KPa})$ & $\phi_{A}\left({ }^{\circ}\right)$ & $\phi_{B}\left({ }^{\circ}\right)$ & $\Psi_{p}\left({ }^{\circ}\right)$ & $\Psi_{s}\left({ }^{\circ}\right)$ & $H(\mathrm{~m})$ & $S$ & $F$ & Moisture & Bayes & Fisher & LR & $\mathrm{NN}$ & $\mathrm{RF}$ & SVM \\
\hline 1 & 27 & 0 & 0 & 30 & 30 & 37.5 & 26 & 110 & Stable & 2.09 & Dry & 1 & 1 & 1 & 1 & 1 & 1 \\
\hline 2 & 26 & 0 & 0 & 30.6 & 22.8 & 30.6 & 33 & 270 & Stable & 1.4 & Dry & 1 & 1 & 1 & 1 & 1 & 1 \\
\hline 3 & 23.24 & 19.15 & 28.73 & 22.6 & 19.1 & 29 & 40 & 46 & Failed & 1 & Dry & 0 & 0 & 0 & 0 & 0 & 0 \\
\hline 4 & 25.14 & 23.94 & 47.88 & 20 & 30 & 31.2 & 65 & 30.5 & Stable & 1.36 & Dry & 1 & 1 & 1 & 1 & 1 & 1 \\
\hline 5 & 27 & 0 & 0 & 15 & 15 & 43 & 26 & 60 & Failed & 0.97 & Dry & 0 & 0 & 0 & 0 & 0 & 0 \\
\hline 6 & 26 & 20 & 20 & 27 & 27 & 60 & 70 & 44 & Stable & 2.35 & Dry & 1 & 1 & 1 & 0 & 1 & 1 \\
\hline 7 & 27 & 0 & 0 & 20 & 30 & 37.5 & 26 & 50 & Stable & 1.65 & Dry & 1 & 1 & 1 & 0 & 1 & 1 \\
\hline 8 & 27 & 0 & 0 & 10 & 10 & 43 & 26 & 60 & Failed & 0.64 & Dry & 0 & 0 & 0 & 0 & 0 & 0 \\
\hline 9 & 26.66 & 0 & 0 & 45 & 45 & 35 & 50 & 150 & Stable & 2.48 & Dry & 1 & 1 & 1 & 1 & 1 & 1 \\
\hline 10 & 20 & 0 & 0 & 40 & 40 & 45 & 60 & 100 & Failed & 0.86 & Dry & 0 & 0 & 0 & 0 & 0 & 0 \\
\hline 11 & 27 & 20 & 20 & 20 & 30 & 43 & 26 & 60 & Stable & 2.18 & Dry & 1 & 1 & 1 & 1 & 1 & 1 \\
\hline 12 & 19.9 & 40 & 19 & 22 & 22 & 37 & 42 & 140 & Failed & 0.9 & Dry & 0 & 0 & 0 & 1 & 0 & 0 \\
\hline 13 & 27 & 0 & 0 & 20 & 30 & 37.5 & 26 & 110 & Stable & 1.65 & Dry & 1 & 1 & 1 & 1 & 1 & 1 \\
\hline 14 & 18.84 & 0 & 0 & 30 & 30 & 37.5 & 45 & 61 & Failed & 0.78 & Dry & 0 & 0 & 0 & 0 & 0 & 0 \\
\hline 15 & 18.84 & 30.07 & 3.6 & 30 & 36.7 & 37.5 & 45 & 61 & Failed & 1.12 & Dry & 0 & 0 & 0 & 0 & 0 & 0 \\
\hline 16 & 26.66 & 0 & 0 & 35 & 35 & 30 & 42 & 150 & Stable & 1.73 & Dry & 1 & 1 & 1 & 1 & 1 & 1 \\
\hline 17 & 26 & 0 & 0 & 39 & 39 & 60 & 70 & 44 & Failed & 0.9 & Dry & 1 & 1 & 1 & 0 & 1 & 1 \\
\hline 18 & 25 & 14.36 & 16.76 & 28 & 18 & 30 & 45 & 37 & Failed & 1 & Dry & 0 & 0 & 0 & 0 & 1 & 0 \\
\hline 19 & 22.8 & 0 & 0 & 35 & 35 & 38 & 47 & 110 & Failed & 1.1 & Dry & 0 & 0 & 0 & 0 & 0 & 0 \\
\hline 20 & 24 & 24.5 & 49 & 20 & 30 & 65 & 31 & 40 & Stable & 1.77 & Dry & 1 & 1 & 1 & 1 & 1 & 1 \\
\hline 21 & 25 & 0 & 0 & 32.4 & 32.4 & 30 & 48 & 50 & Stable & 1.9 & Dry & 0 & 0 & 0 & 0 & 1 & 1 \\
\hline 22 & 27 & 0 & 0 & 20 & 30 & 43 & 26 & 50 & Stable & 1.65 & Dry & 1 & 1 & 1 & 0 & 1 & 1 \\
\hline
\end{tabular}

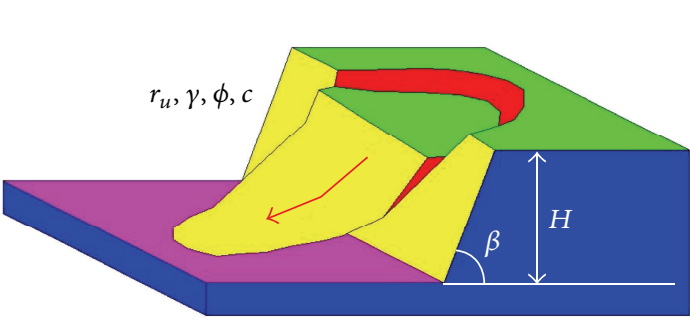

(a)

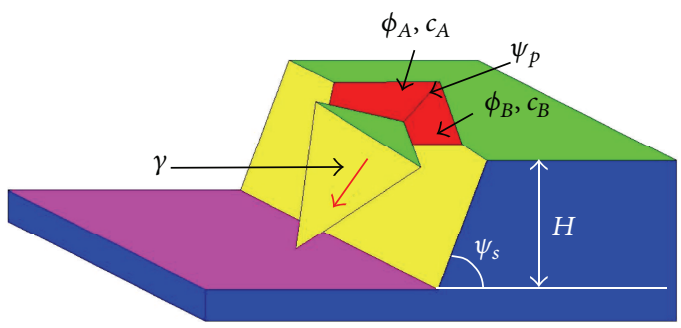

(b)

FIGURE 1: Failure models: (a) circular failure mechanism and (b) wedge failure mechanism.

the NBC under certain conditions even when the conditional independence assumption is violated.

This probability calculation is straightforward; conditioning on the observed attributes, we want to find the probability that $I$ belongs to each category, that is, $P\left(I \in C_{i} \mid\right.$ $\left.X_{1}, X_{2}, \ldots, X_{n}\right)$.

Applying Bayes' Theorem [39], this is rewritten as

$$
\begin{aligned}
P\left(I \in C_{i} \mid X_{1}, X_{2}, \ldots, X_{n}\right) & \\
= & \frac{P\left(I \in C_{i}\right) P\left(X_{1}, X_{2}, \ldots, X_{n} \mid I \in C_{i}\right)}{P\left(X_{1}, X_{2}, \ldots, X_{n}\right)} .
\end{aligned}
$$

Under the mutual conditional independence assumption [39], this reduces to

$P\left(I \in C_{i} \mid X_{1}, X_{2}, \ldots, X_{n}\right)=\frac{P\left(I \in C_{i}\right) \prod_{j=1}^{n} P\left(X_{j} \mid I \in C_{i}\right)}{P\left(X_{1}, X_{2}, \ldots, X_{n}\right)}$ for each category $C_{i}$. Since the denominator will be the same for all categories, we only need to calculate the numerator for each category $i$, choosing

$$
i^{*} \in \arg \max P\left(I \in C_{i}\right) \prod_{j=1}^{n} P\left(X_{j} \mid I \in C_{i}\right)
$$

and assigning $I$ to category $C_{i^{*}}$. Then, the probability that an event $I$ belongs to category $C_{i}$ is computed by (2).

In the present study, unit weight $(\gamma)$, cohesion $(c)$, angle of internal friction $(\phi)$, slope angle $(\beta)$, height $(H)$, and pore water pressure $\left(r_{u}\right)$ for circular failure mechanism were expressed as $X_{1}, X_{2}, X_{3}, X_{4}, X_{5}$, and $X_{6}$. The implementation was through the SPSS software with actual sizes of samples as a priori probabilities, and the discriminant function was given as follows:

$$
\begin{aligned}
Y_{\text {Failed }}= & 1.6940 X_{1}-0.0891 X_{2}-0.3232 X_{3}+0.6099 X_{4} \\
& -0.0186 X_{5}+8.1056 X_{6}-22.9527
\end{aligned}
$$




$$
\begin{aligned}
Y_{\text {Stable }}= & 1.9005 X_{1}-0.0341 X_{2}+0.0287 X_{3}+0.2657 X_{4} \\
& -0.0603 X_{5}-1.1166 X_{6}-24.3608
\end{aligned}
$$

For the case of wedge failure mechanism, unit weight $(\gamma)$, cohesions $\left(c_{A}\right)$ and $\left(c_{B}\right)$, angles of internal friction $\left(\phi_{A}\right)$ and $\left(\phi_{B}\right)$, angle of the line of intersection of the two joint sets $\left(\psi_{p}\right)$, slope angle $\left(\psi_{s}\right)$, and height $(H)$ are expressed as $X_{w 1}, X_{w 2}$, $X_{w 3}, X_{w 4}, X_{w 5}, X_{w 6}, X_{w 7}$, and $X_{w 8}$. Bayes' functions are given as follows:

$$
\begin{aligned}
Y_{\text {Failed }}= & 15.14 X_{w 1}-0.53 X_{w 2}-0.82 X_{w 3}-1.60 X_{w 4} \\
& +4.57 X_{w 5}+1.16 X_{w 6}+0.31 X_{w 7}+0.36 X_{w 8} \\
& -253.77 \\
Y_{\text {Stable }}= & 17.98 X_{w 1}-0.42 X_{w 2}-1.22 X_{w 3}-2.28 X_{w 4} \\
& +5.90 X_{w 5}+1.45 X_{w 6}+0.30 X_{w 7}+0.47 X_{w 8} \\
& -365.60
\end{aligned}
$$

According to the above established models, the results of circular failure mechanism and wedge failure mechanism cases were obtained and listed in Tables 1 and 2, respectively.

2.5. Fisher's Classification Models. Fisher's discriminant analysis is a classification method that projects high-dimensional data onto a line and performs classification in this onedimensional space, which is widely used to determine which variable discriminates between two or more classes and to derive a classification model for predicting the group membership of new observations with high accuracy [14-16, 43, 44]. In the present work, the Fisher discriminant analysis was used to establish discriminator for discriminating between failed and stable statuses of slope.

Based on the Fisher discriminant theory, the score of Fisher discriminator can be calculated by

$$
Y_{\text {Fisher }}=C_{0}+\sum_{i=1}^{n} C_{i} X_{i}
$$

where $C_{i}$ is the coefficient of the Fisher discriminator. And the Fisher scores of the center for failed and stable statusescan be calculated as $\bar{Y}_{f}$ and $\bar{Y}_{s}$, respectively. Then, the threshold can be obtained by $0.5\left(\bar{Y}_{f}+\bar{Y}_{s}\right)$. Every case has a set of values of $X_{i}$, and corresponding to a Fisher score, if the Fisher score is greater than the threshold, the slope belongs to stable the slope, otherwise to the failed slope.

The indicators unit weight $(\gamma)$, cohesion $(c)$, angle of internal friction $(\phi)$, slope angle $(\beta)$, height $(H)$, and pore water pressure $\left(r_{u}\right)$ for circular failure mechanism are also expressed as $X_{1}, X_{2}, X_{3}, X_{4}, X_{5}$, and $X_{6}$. The calculation was executed through the SPSS software. The discriminant function is

$$
\begin{aligned}
Y_{\text {Fisher }}= & -0.09 X_{1}-0.02 X_{2}-0.15 X_{3}+0.14 X_{4} \\
& +0.02 X_{5}+3.87 X_{6}+0.04
\end{aligned}
$$

The $\bar{Y}_{f}$ and $\bar{Y}_{s}$ are 0.874 and -1.509 , respectively.

For the case of wedge failure mechanism, as in Section 2.4, unit weight $(\gamma)$, cohesions $\left(c_{A}\right)$ and $\left(c_{B}\right)$, angles of internal friction $\left(\phi_{A}\right)$ and $\left(\phi_{B}\right)$, angle of the line of intersection of the two joint sets $\left(\psi_{p}\right)$, slope angle $\left(\psi_{s}\right)$, and height $(H)$ are also expressed as $X_{w 1}, X_{w 2}, X_{w 3}, X_{w 4}, X_{w 5}$, $X_{w 6}, X_{w 7}$, and $X_{w 8}$. The Fisher discriminant function is given as follows, and the $\bar{Y}_{f}$ and $\bar{Y}_{s}$ are -2.743 and 2.134, respectively, as

$$
\begin{aligned}
Y_{\text {Fisher }}= & 0.58 X_{w 1}-0.02 X_{w 2}+0.08 X_{w 3}-0.14 X_{w 4} \\
& +0.27 X_{w 5}+0.06 X_{w 6}+0.003 X_{w 7}+0.02 X_{w 8} \\
& -23.23
\end{aligned}
$$

According to the above established Fisher models, the results of circular failure mechanism and wedge failure mechanism cases were also obtained and listed in Tables 1 and 2, respectively.

2.6. Logistic Regression Models. Logistic regression (LR) is a statistical modeling technique in which the probability of a category is related to a set of explanatory variables. An explanation of logistic regression begins with an explanation of the logistic function, which always takes values between zero and one. The logistic model is defined by the following equations:

$$
\begin{gathered}
z=a_{0}+\sum_{i=1}^{n} a_{i} x_{i}, \\
P(z)=\frac{e^{z}}{1+e^{z}},
\end{gathered}
$$

where $z$ is a measure of the contribution of the explanatory variables $x_{i}(i=1, \ldots, n), a_{i}$ are the regression coefficients which are obtained by maximum likelihood in conjunction with their standard errors $\Delta a_{i}$, and $P(z)$ is the categorical response of variables that represents the probability of a particular outcome. In this particular application, $x_{i}$ are the slope rockmass parameters of interest, and $P(z)$ is the probability of having stable and failed statuses. The calculation of LR is finished through the SPSS software, and logistic functions for circular failure mechanism and wedge failure mechanism cases are given as follows:

$$
\begin{gathered}
P\left(z_{c}\right)=\frac{e^{0.459 x_{1}-0.145 x_{2}+0.515 x_{3}-0.47 x_{4}-0.147 x_{5}-13.936 x_{6}-4.262}}{1+e^{0.459 x_{1}-0.145 x_{2}+0.515 x_{3}-0.47 x_{4}-0.147 x_{5}-13.936 x_{6}-4.262}}, \\
P\left(z_{w}\right)=\frac{e^{8.201 x_{w 1}+0.567 x_{w 2}+0.344 x_{w 3}-1.264 x_{w 4}+3.185 x_{w 5}+0.558 x_{w 6}-0.05 x_{w 7}+0.225 x_{w 8}-304.38}}{1+e^{8.201 x_{w 1}+0.567 x_{w 2}+0.344 x_{w 3}-1.264 x_{w 4}+3.185 x_{w 5}+0.558 x_{w 6}-0.05 x_{w 7}+0.225 x_{w 8}-304.38}} .
\end{gathered}
$$


The threshold of the above two logistic regression models is 0.5 , and the results are listed in Tables 1 and 2 .

2.7. Neural Networks Models. Neural networks (NNs) have long been used in problems such as this, with a lot of data, many variables, and the possibility of noise in the data.

Each input point is a high-dimensional vector. The neural network is organized in a series of layers, where the input vector enters at the left side of the network, which is then projected to a "hidden layer." Each unit in the hidden layer is a weighed sum of the values in the first layer. This layer then projects to an output layer, which is where the desired answer appears.

In the present work, a multi-layer perceptron network model is used. Training took place for the specific range of values that cover the training dataset. Trying to achieve the best network's performance, several networks with different architectures were developed using all of the possible variations of the backpropagation algorithms available in MATLAB 2010b. The final network architecture for the prediction of safety factor against circular failure it is (6-10-1), whereas in the case of wedge failure is (8-12-1). The learning rate was set to 0.01 and the error goal was set to 0.0001 . The results for circular failure mechanism and wedge failure mechanism are listed in Tables 1 and 2, respectively.

\section{Comparisons and Discussions}

The ROC curve is used to evaluate and compare the established RF, SVM, Bayes, Fisher, LR, and NN classification models in slope stability evaluation. ROC is a graphical plot which illustrates the performance of a binary classifier system as its discrimination threshold is varied [45]. It is created by plotting the fraction of true positives out of the positives (TPR $=$ true positive rate) versus the fraction of false positives out of the negatives (FPR = false positive rate), at various threshold settings.

ROC analysis provides tools to select possibly optimal models and to discard suboptimal ones independently from (and prior to specifying) the cost context or the class distribution. ROC analysis is related in a direct and natural way to cost/benefit analysis of diagnostic decision making.

In the present study, the stable and failed statuses of slope were considered a two-class prediction problem (binary classification), in which the outcomes were labeled either as positive ( $p$, stable) or negative ( $n$, failed). There are four possible outcomes from a binary classifier. If the outcome from a prediction is $p^{\prime}$ and the actual value is also $p$, then it is called true positive (TP); however, if the actual value is $n$, then it is said to be false positive (FP). Conversely, a true negative (TN) value has occurred when both the prediction outcome and the actual value are $n$, and a false negative $(\mathrm{FN})$ value is when the prediction outcome is $n^{\prime}$ while the actual value is $p$.

An experiment from $p$ positive and $n$ negative was defined for instances. The four outcomes can be formulated in a $2 \times 2$ contingency table or a confusion matrix, as follows in Table 3.
TABLE 3: Contingency matrix for the two-class prediction problem.

\begin{tabular}{lcccc}
\hline \multicolumn{4}{c}{ Actual value } & Total \\
& $p$ & $n$ & \\
\hline Prediction & $p^{\prime}$ & True positive (TP) & False positive (FP) & $p$ \\
outcome & $n^{\prime}$ & False negative (FN) & True negative (TN) & $n$ \\
Total & & $p$ & $n$ & \\
\hline
\end{tabular}

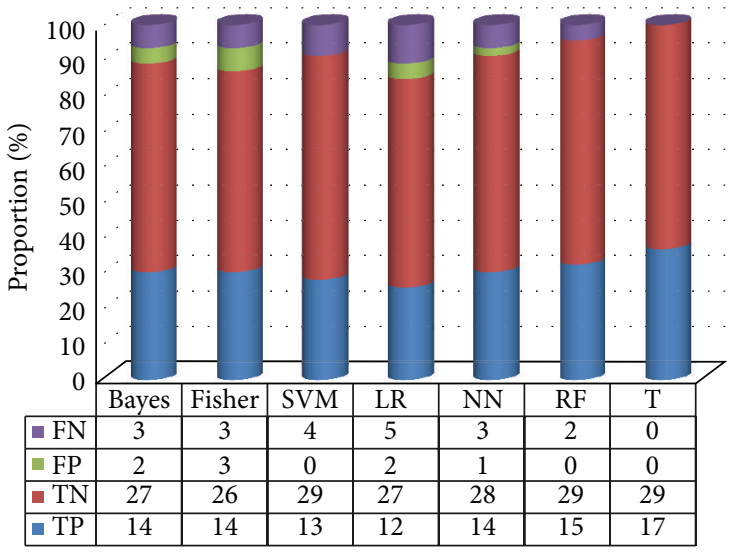

(a)

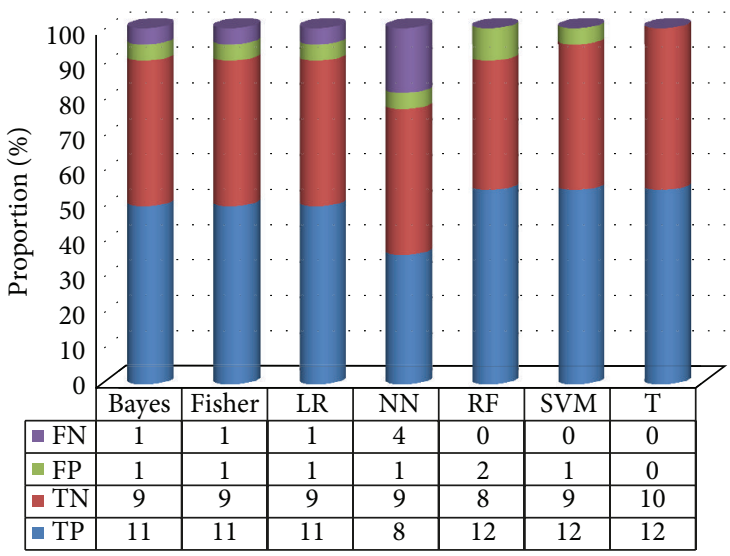

(b)

Figure 2: Proportions of TP, TN, FP, and FN for the RF, SVM, Bayes, Fisher, LR, and NN classification models: (a) circular failure mechanism and (b) wedge failure mechanism.

The specificity or the true negative rate (TNR) is defined as the percentage of slope which is correctly identified as being failed:

$$
\text { Specificity }=\frac{\mathrm{TN}}{\mathrm{TN}+\mathrm{FP}} .
$$

The quantity $1-$ specificity is the false positive rate and is the percentage of slopes that are incorrectly identified as being stable statuses. The sensitivity or the true positive rate (TPR) is defined as the percentage of slope which is correctly identified as being stable status:

$$
\text { Sensitivity }=\frac{\mathrm{TP}}{\mathrm{TP}+\mathrm{FN}} \text {. }
$$




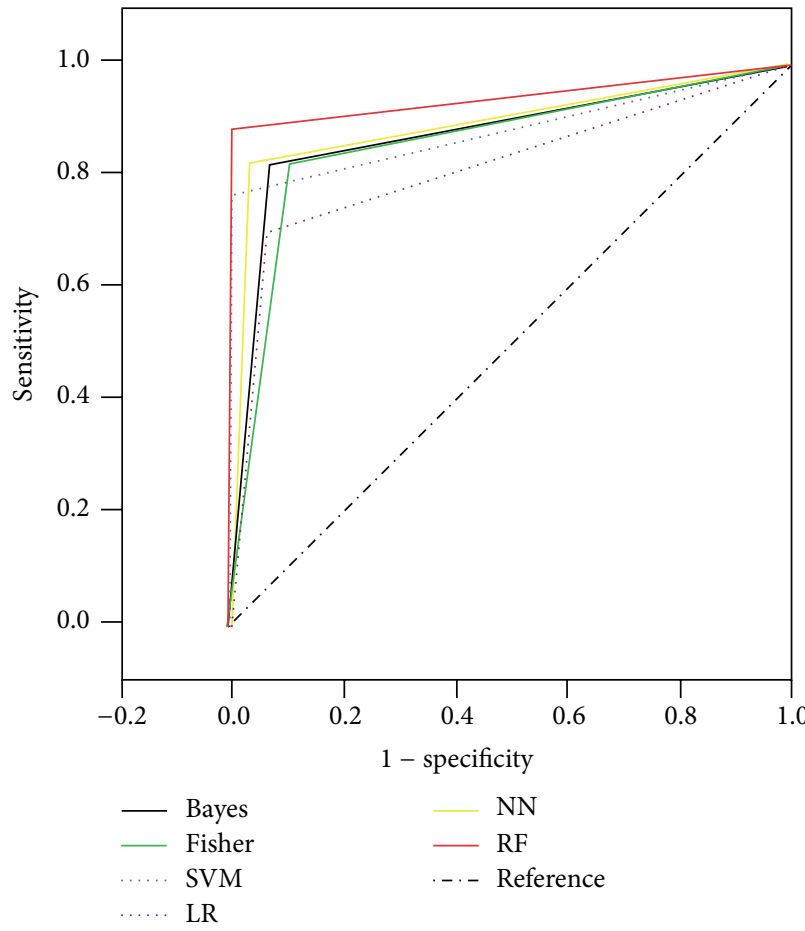

(a)

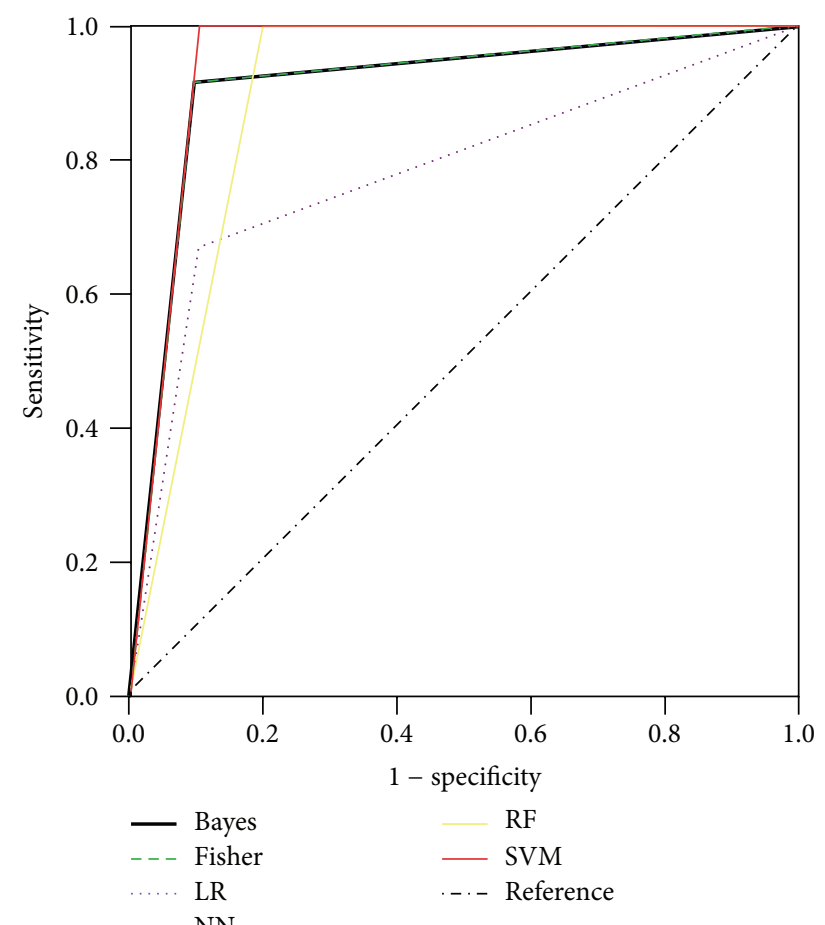

(b)

FIGURE 3: ROC curves for the RF, SVM, Bayes, Fisher, LR, and NN classification models: (a) circular failure mechanism and (b) wedge failure mechanism.

TABLE 4: Areas under ROC curves for cases of circular failure mechanism.

\begin{tabular}{|c|c|c|c|c|c|}
\hline \multirow{2}{*}{ Methods } & \multirow{2}{*}{ Areas } & \multirow{2}{*}{ Standard error } & \multirow{2}{*}{$P$ value } & \multicolumn{2}{|c|}{$95 \%$ confidence interval } \\
\hline & & & & Upper & Lower \\
\hline Bayes & 0.877 & 0.061 & 0.0000 & 0.7573 & 0.9973 \\
\hline Fisher & 0.860 & 0.064 & 0.0001 & 0.7355 & 0.9846 \\
\hline SVM & 0.882 & 0.064 & 0.0000 & 0.7579 & 1.0000 \\
\hline LR & 0.819 & 0.073 & 0.0004 & 0.6757 & 0.9612 \\
\hline $\mathrm{BP}$ & 0.895 & 0.059 & 0.0000 & 0.7794 & 1.0000 \\
\hline $\mathrm{RF}$ & 0.941 & 0.047 & 0.0000 & 0.8497 & 1.0000 \\
\hline
\end{tabular}

For the cases of circular failure mechanism, the proportions of TP, TN, FP, and FN for the RF, SVM, Bayes, Fisher, LR, and NN classification models are shown in Figure 2(a). ROC curves are shown in Figure 3(a). And the areas under the ROC curves of RF, SVM, Bayes, Fisher, LR, and NN classification models are listed in Table 4. Figure 2(a) shows that the accuracy of RF model is the highest with the TP of 15 and TN of 29. Figure 3(a) and Table 4 show that RF has the biggest area (0.941), followed by NN (0.895), SVM (0.882), Bayes (0.877), Fisher (0.860), and LR (0.819). For the cases of wedge failure mechanism, the proportions of TP, TN, FP, and FN for RF, SVM, Bayes, Fisher, LR, and NN classifiers are shown in Figure 2(b). ROC curves are shown in Figure 3(b). And the areas under ROC curves of RF, SVM, Bayes, Fisher, LR, and NN classifiers are listed in Table 5. Figure 2(b) shows that the accuracy of SVM models is the highest with the TP of 12 and TN of 9. Figure 3(b) and Table 5 show that SVM has the biggest area (0.95), and followed by Bayes' and Fisher models, and LR, which have the same area (0.908), and then followed by RF (0.9) and NN (0.783). Figures 2(a) and 2(b) clearly show that both the RF and SVM models have the highest TP and TN. It is suggested that the evaluated methods for different failure mechanism slopes are different, and RF and SVM models can be the preferred ones for circular failure and wedge failure landslides, respectively. It is noted that the trained and calibrated models are influenced by the size of training samples, and the reliability and applicability of the proposed models in this paper can be improved with increasing training samples.

\section{Conclusions}

This paper demonstrates the applicability and feasibility of the RF, SVM, Bayes (NBC), Fisher, LR, and NN classification 
TABLE 5: Areas under ROC curves for cases of wedge failure mechanism.

\begin{tabular}{lcccc}
\hline Methods & Areas & Standard error & P value & \multicolumn{2}{c}{ 95\% confidence interval } \\
Lpper
\end{tabular}

models to evaluate the rockmass stability of slopes. Samples of both circular failure mechanism and wedge failure mechanism were considered to establish and calibrate discriminant models. The classification performances of different modeling approaches are analyzed and compared by ROC curves. Results show that the established RF, SVM, Bayes, Fisher, LR, and NN classification models can evaluate the slope statuses with a high accuracy. RF models have the highest accuracy for slope cases for circular failure mechanism, while SVM models have the highest accuracy for slope cases for wedge failure mechanism. Both the RF and SVM models have the highest TP and TN. It is suggested that the established models for different failure mechanism slopes are different, and RF and SVM models can be the preferred ones for evaluating the stability of circular failure and wedge failure landslides, respectively.

\section{Conflict of Interests}

The authors declare that there is no conflict of interests regarding the publication of this paper.

\section{Acknowledgments}

The support of the National Natural Science Foundation of China (50934006), National Basic Research (973) Program of China (2010CB732004), China Scholarship Council, Doctoral Candidate Innovation Research Support Program by Science \& Technology Review (kjdb201001-7), and Scholarship Award for Excellent Doctoral Student from Ministry of Education of China is gratefully acknowledged.

\section{References}

[1] M. G. Sakellariou and M. D. Ferentinou, "A study of slope stability prediction using neural networks," Geotechnical and Geological Engineering, vol. 23, no. 4, pp. 419-445, 2005.

[2] L.-J. Dong and X.-B. Li, "Interval non-probabilistic reliability method for surrounding jointed rock mass stability of underground caverns," Chinese Journal of Geotechnical Engineering, vol. 33, no. 7, pp. 1007-1013, 2011.

[3] L.-J. Dong and X.-B. Li, "Interval parameters and credibility of representative values of tensile and compression strength tests on rock," Chinese Journal of Geotechnical Engineering, vol. 32, no. 12, pp. 1969-1974, 2010.
[4] L. Dong, X. Li, and Z. Zhou, "Nonlinear model-based support vector machine for predicting rock mechanical behaviors," Advanced Science Letters, vol. 5, pp. 806-810, 2012.

[5] B. Rajesh Kumar, H. Vardhan, M. Govindaraj, and G. Vijay, "Regression analysis and ANN models to predict rock properties from sound levels produced during drilling," International Journal of Rock Mechanics and Mining Sciences, vol. 58, pp. 6172, 2013.

[6] S. Kundu, A. Saha, D. Sharma, and C. Pant, "Remote sensing and GIS based landslide susceptibility assessment using binary logistic regression model: a case study in the Ganeshganga Watershed, Himalayas," Journal of the Indian Society of Remote Sensing, 2013.

[7] H. R. Pourghasemi, A. G. Jirandeh, B. Pradhan, C. Xu, and C. Gokceoglu, "Landslide susceptibility mapping using support vector machine and GIS at the Golestan Province, Iran," Journal of Earth System Science, vol. 122, no. 2, pp. 349-369, 2013.

[8] S. Pascale, S. Parisi, A. Mancini et al., "Landslide susceptibility mapping using artificial neural network in the urban area of Senise and San Costantino Albanese (Basilicata, Southern Italy)," in Computational Science and Its Applications-ICCSA 2013, pp. 473-488, Springer, 2013.

[9] H. Wang, J. Li, B. Zhou, Z. Yuan, and Y. Chen, "Application of a hybrid model of neural networks and genetic algorithms to evaluate landslide susceptibility," Natural Hazards and Earth System Sciences Discussions, vol. 1, pp. 353-388, 2013.

[10] M. Venkatesan, A. Thangavelu, and P. Prabhavathy, "An improved Bayesian classification data mining method for early warning landslide susceptibility model using GIS," in Proceedings of the 7th International Conference on Bio-Inspired Computing: Theories and Applications (BIC-TA '12), pp. 277-288, 2013.

[11] D. T. Bui, B. Pradhan, O. Lofman, I. Revhaug, and Ø. B. Dick, "Regional prediction of landslide hazard using probability analysis of intense rainfall in the Hoa Binh province, Vietnam," Natural Hazards, vol. 66, no. 2, pp. 707-730, 2013.

[12] L. Dong, X. Li, and K. Peng, "Prediction of rockburst classification using Random Forest," Transactions of Nonferrous Metals Society of China, vol. 23, pp. 472-477, 2013.

[13] A. C. Adoko, C. Gokceoglu, L. Wu, and Q. J. Zuo, "Knowledgebased and data-driven fuzzy modeling for rockburst prediction," International Journal of Rock Mechanics and Mining Sciences, vol. 61, pp. 86-95, 2013.

[14] L. Dong, X. Li, G. Zhao, and F. Gong, "Fisher discriminant analysis model and its application to predicting destructive effect of masonry structure under blasting vibration of openpit mine," Chinese Journal of Rock Mechanics and Engineering, vol. 28, no. 4, pp. 750-756, 2009. 
[15] L. J. Dong, F. Y. Wang, Y. F. Bai, and Y. F. Liu, "A Fisher discriminant analysis model for prediction of seismic liquefaction of sand soil," Near-Surface Geophysics and Human Activity, pp. 146-150, 2008.

[16] L. J. Dong, Y. H. Fu, Y. F. Liu, and Y. F. Bai, "A Fisher discriminant analysis model for classification of rocks surrounding in tunnel," in Proceedings of the Information Technology and Environmental System Sciences (Itess '08), vol. 2, pp. 632-636, 2008.

[17] L. J. Dong, D. T. Hu, Y. F. Bai, and Y. F. Liu, "Unascertained average grade model for surrounding rock classification on hydraulic tunnels," Progress in Safety Science and Technology, vol. 7, pp. 2227-2231, 2008.

[18] L.-J. Dong, X.-B. Li, and Y.-F. Bai, "A Fisher discriminant analysis model for classifying top coal cavability of the steep seam," Journal of the China Coal Society, vol. 34, no. 1, pp. 58-63, 2009.

[19] L. Dong and F. Wang, "Comprehensive evaluation seismic stability of slopes based on unascermined measurcmem," The Chinese Journal of Geological Hazard and Control, vol. 18, pp. 74-78, 2007.

[20] L. Dong and X. Li, "An application of grey-general regression neural network for predicting landslide deformation of Dahu Mine in China," Advanced Science Letters, vol. 6, pp. 577-581, 2012.

[21] X. B. Li, L. J. Dong, G. Y. Zhao et al., "Stability analysis and comprehensive treatment methods of landslides under complex mining environment-A case study of Dahu landslide from Linbao Henan in China," Safety Science, vol. 50, no. 4, pp. 695704, 2012

[22] T. N. Singh, R. Kanchan, K. Saigal, and A. K. Verma, "Prediction of p-wave velocity and anisotropic property of rock using artificial neural network technique," Journal of Scientific and Industrial Research, vol. 63, no. 1, pp. 32-38, 2004.

[23] H. Vardhan, G. R. Adhikari, and M. Govinda Raj, "Estimating rock properties using sound levels produced during drilling," International Journal of Rock Mechanics and Mining Sciences, vol. 46, no. 3, pp. 604-612, 2009.

[24] R. Huang, J. Huang, N. Ju, and Y. Li, "Automated tunnel rock classification using rock engineering systems," Engineering Geology, vol. 156, pp. 20-27, 2013.

[25] A. Khabbazi, M. Ghafoori, G. Lashkaripour, and A. Cheshomi, "Estimation of the rock mass deformation modulus using a rock classification system," Geomechanics and Geoengineering, vol. 8, pp. 46-52, 2013.

[26] K. Manoj and M. Monjezi, "Prediction of flyrock in open pit blasting operation using machine learning method," International Journal of Mining Science and Technology, vol. 23, no. 3, pp. 313-316, 2013.

[27] L. Dong, X. Li, M. Xu, and Q. Li, "Comparisons of random forest and support vector machine for predicting blasting vibration characteristic parameters," in Proceedings of the 1st International Symposium on Mine Safety Science and Engineering (ISMSSE '11), vol. 26, pp. 1772-1781, October 2011.

[28] A. Salimi and M. Esmaeili, "Utilising of linear and non-linear prediction tools for evaluation of penetration rate of tunnel boring machine in hard rock condition," International Journal of Mining and Mineral Engineering, vol. 4, pp. 249-264, 2013.

[29] A. Verma and T. Singh, "Comparative study of cognitive systems for ground vibration measurements," Neural Computing and Applications, vol. 22, no. 1, supplement, pp. 341-350, 2013.

[30] A. K. Verma and T. N. Singh, "A neuro-fuzzy approach for prediction of longitudinal wave velocity," Neural Computing and Applications, vol. 22, no. 7-8, pp. 1685-1693, 2013.
[31] J. Xing, A. Jiang, Z. Wen, and J. Qin, "A nonlinear optimization technique of tunnel construction based on DE and LSSVM," Mathematical Problems in Engineering, vol. 2013, Article ID 980154, 11 pages, 2013.

[32] O. Saeidi, S. R. Torabi, and M. Ataei, "Prediction of the rock mass diggability index by using fuzzy clustering-based, ANN and multiple regression methods," Rock Mechanics and Rock Engineering, 2013.

[33] T. Wang, L. Cai, Y. Fu, and T. Zhu, "A wavelet-based robust relevance vector machine based on sensor data scheduling control for modeling mine gas gushing forecasting on virtual environment," Mathematical Problems in Engineering, vol. 2013, Article ID 579693, 4 pages, 2013.

[34] Y. L. Tsai, "Rainfall reliability evaluation for stability of municipal solid waste landfills on slope," Mathematical Problems in Engineering, vol. 2013, Article ID 653282, 10 pages, 2013.

[35] P. Samui and D. Kim, "Determination of reservoir induced earthquake using support vector machine and Gaussian process regression," Applied Geophysics, vol. 10, pp. 229-234, 2013.

[36] L. Dong, X. Li, C. Ma, and W. Zhu, "Comparisons of logistic regression and Fisher discriminant classifier to seismic event identification," Disaster Advances, vol. 6, p. 8, 2013.

[37] P. Samui, "Multivariate adaptive regression spline (Mars) for prediction of elastic modulus of jointed rock mass," Geotechnical and Geological Engineering, vol. 31, pp. 249-253, 2013.

[38] L. Breiman, "Random forests," Machine Learning, vol. 45, no. 1, pp. 5-32, 2001.

[39] F. Wang, L. Dong, and Z. Xu, "Phreatic line predicted methodbased SVM for stability analysis of tailing dam," Applied Mechanics and Materials, vol. 44-47, pp. 3398-3402, 2011.

[40] P. Berchialla, F. Foltran, and D. Gregori, "Naïve Bayes classifiers with feature selection to predict hospitalization and complications due to objects swallowing and ingestion among European children," Safety Science, vol. 51, pp. 1-5, 2013.

[41] Y.-H. Fu and L.-J. Dong, "Bayes discriminant analysis model and its application to the prediction and classification of rockburst," Journal of China University of Mining and Technology, vol. 38, no. 4, pp. 528-533, 2009.

[42] P. Domingos and M. Pazzani, "On the optimality of the simple Bayesian classifier under zero-one loss," Machine Learning, vol. 29, no. 2-3, pp. 103-130, 1997.

[43] A. P. Worth and M. T. D. Cronin, "The use of discriminant analysis, logistic regression and classification tree analysis in the development of classification models for human health effects," Journal of Molecular Structure: THEOCHEM, vol. 622, no. 1-2, pp. 97-111, 2003.

[44] Y. Bai, J. Deng, L. Dong, and X. Li, "Application of Fisher discriminant method in goaf collapse prediction," Mining Research and Development, vol. 28, no. 5, p. 5, 2008.

[45] A. P. Bradley, "The use of the area under the ROC curve in the evaluation of machine learning algorithms," Pattern Recognition, vol. 30, no. 7, pp. 1145-1159, 1997. 


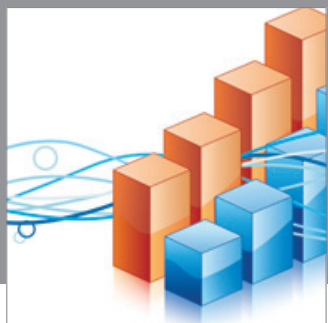

Advances in

Operations Research

mansans

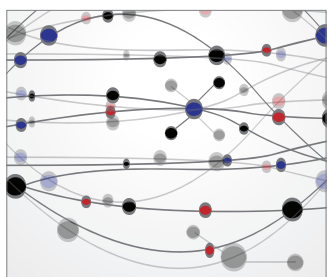

The Scientific World Journal
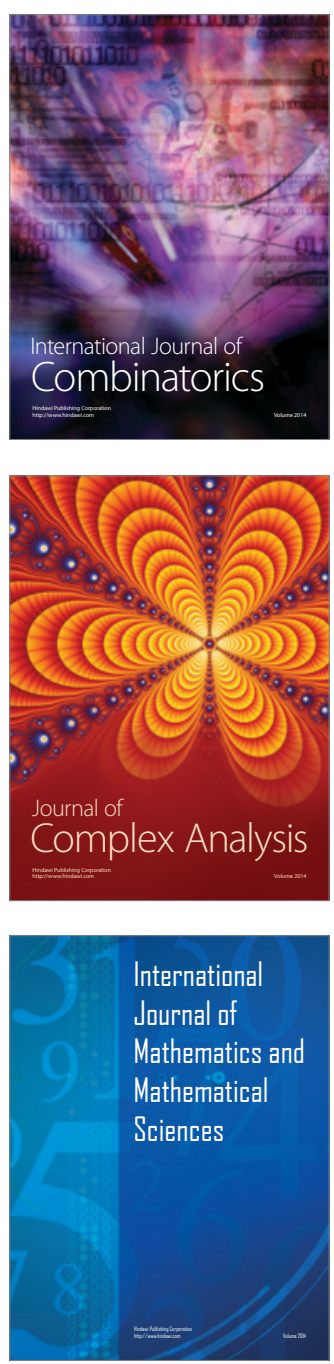
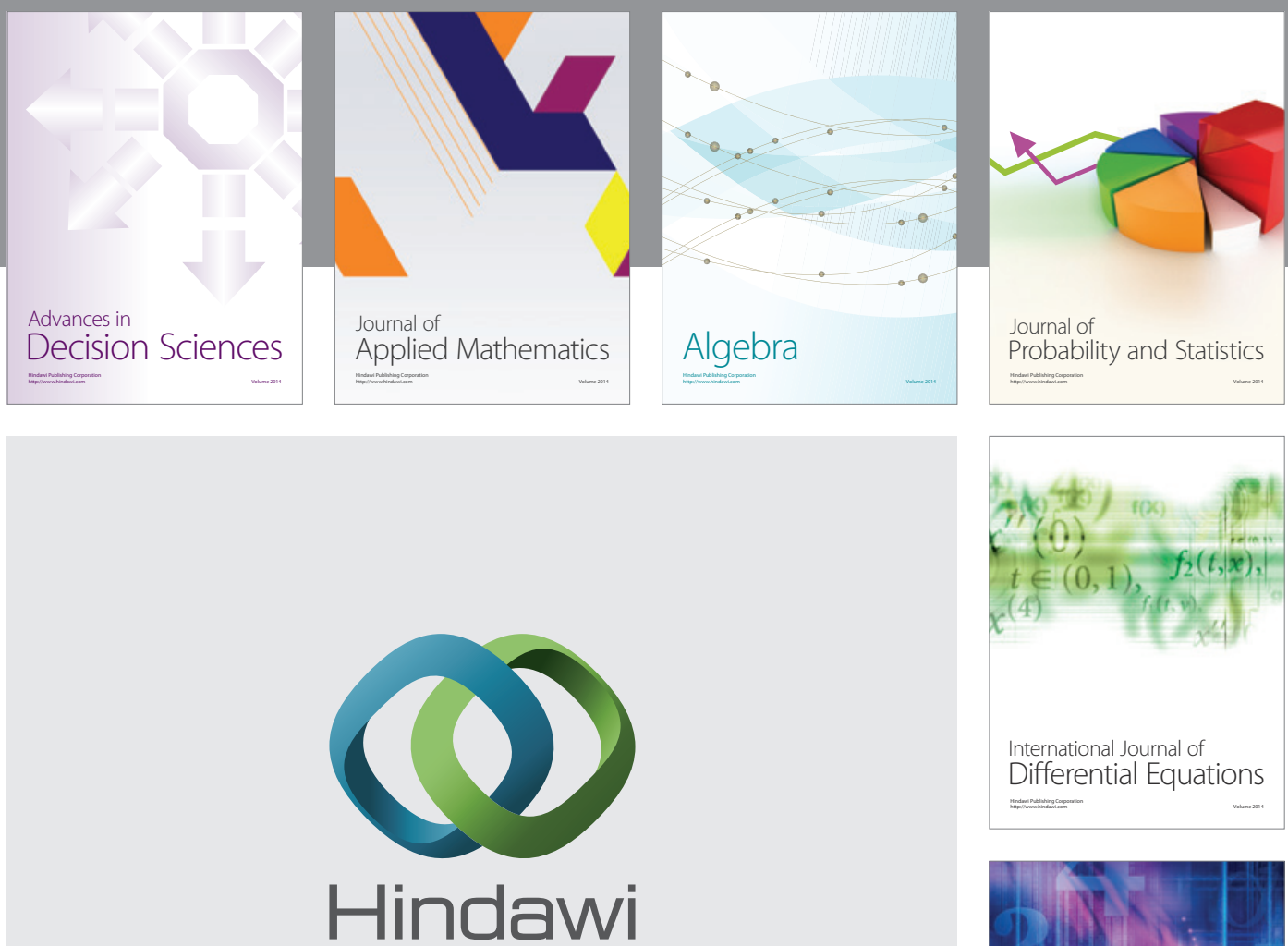

Submit your manuscripts at http://www.hindawi.com
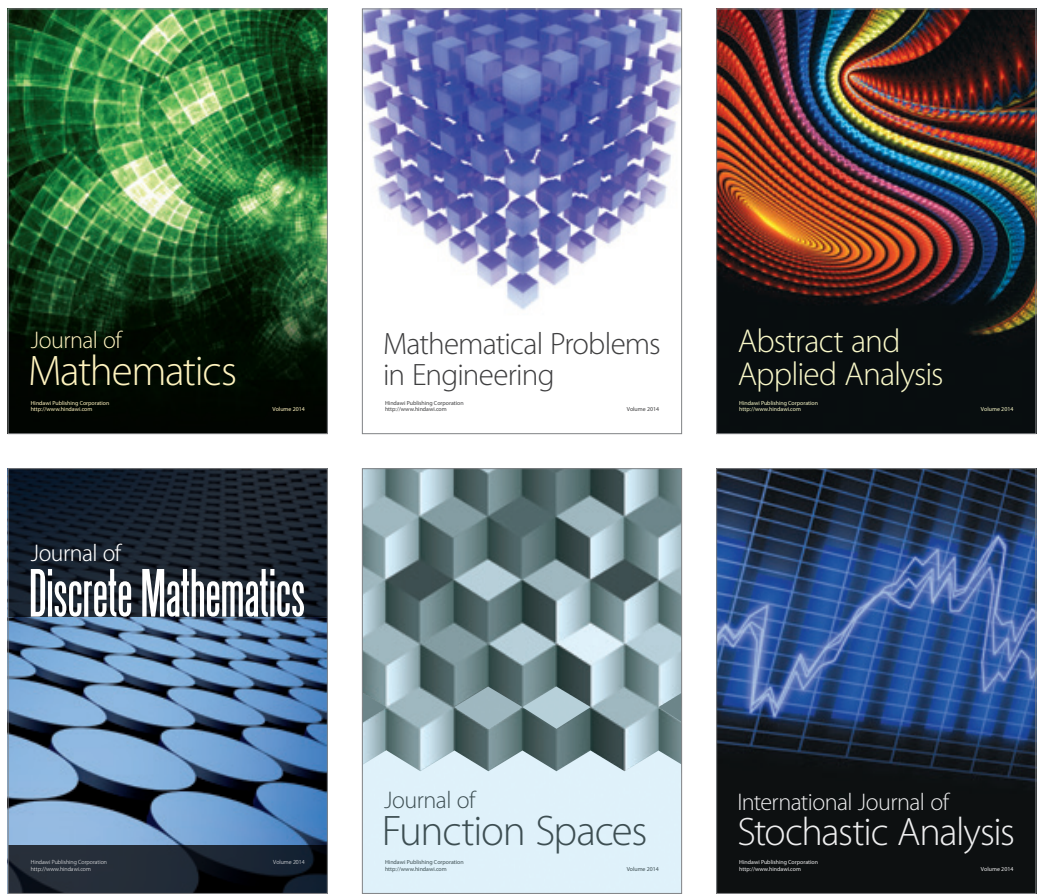

Journal of

Function Spaces

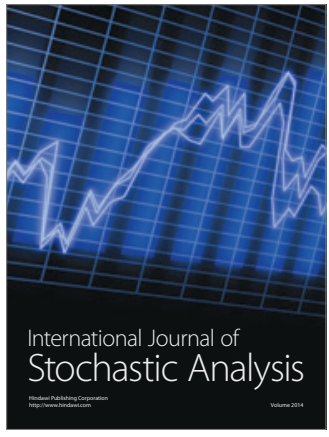

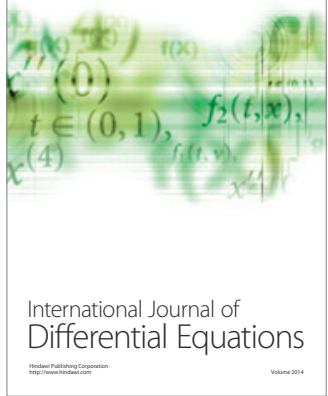
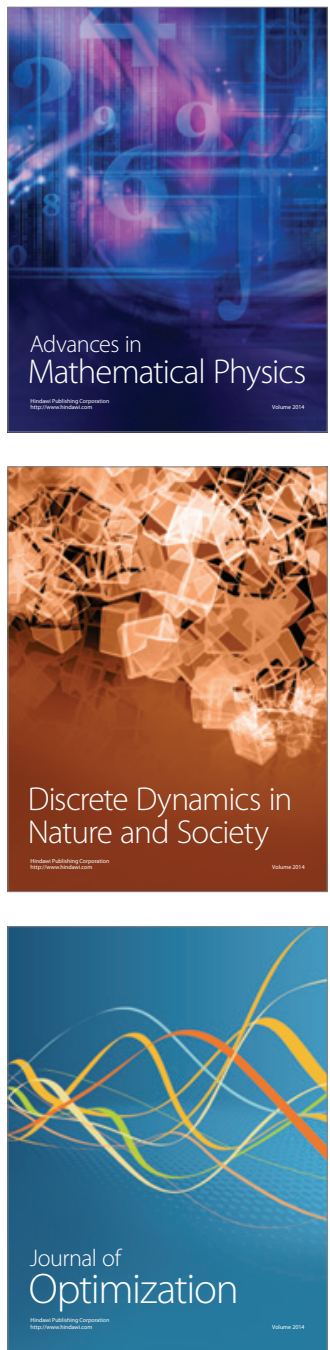